\title{
PRODUÇÃO ACADÊMICA EM EMPREENDEDORISMO \\ NO BRASIL: ANÁLISE DOS ARTIGOS APROVADOS \\ NOS EVENTOS DA ANPAD ENTRE 2001 E 2012
}

\author{
BRAZIL'S ACADEMIC PRODUCTION IN ENTREPRENEURSHIP: \\ AN ANALYSIS OF PAPERS APPROVED AT ANPAD EVENTS \\ FROM 2001 TO 2012
}

Recebido em: 03/07/2015• Aprovado em: 14/09/2015 Avaliado pelo sistema double blind review Editora Científica: Manolita Correia Lima DOI: $10.13058 /$ raep.2015.v16n 4.383

\author{
EDSONSADAO IIZUKA esadao@fei.edu.br \\ CENTRO UNIVERSITÁRIO FEI
}

\section{GUSTAVO HERMÍNIO SALATI MARCONDES DE MORAES}

FACULDADE DE CIÊNCIAS APLICADAS - UNIVERSIDADE ESTADUAL DE CAMPINAS

\author{
ANDERSON DE ANDRADE SANTOS \\ INSTITUTO DE ENSINO E PESQUISA (INSPER)
}

\begin{abstract}
RESUMO
Trata-se de um artigo que busca analisar a produção acadêmica brasileira com a temática do empreendedorismo, especificamente sobre o que foi produzido no âmbito dos encontros promovidos pela ANPAD: EMA, EnEO, Simpósio, EnEPQ, 3 Es, EnGPR, EnAPG e EnANPAD entre $200 \mathrm{I}$ e 20I2. Os principais pesquisadores brasileiros sobre o empreendedorismo lançam, nestes eventos, os seus questionamentos e as suas pautas de interesses, constituindose, portanto, num espaço privilegiado para compreender-se o estado da arte nesta temática, assim como tendências relevantes. Adotou-se a pesquisa exploratória, de cunho misto, qualitativo quanto à parte bibliográfica e análise de conteúdo e quantitativo na parte correspondente à estatística descritiva. Foi analisado um total de 150 artigos que continham no título a expressão "empreendedorismo", localizados pelo sistema de busca eletrônico da ANPAD. Após a análise das 5.25I referências utilizadas nos artigos verificou-se que 22 autores foram os mais utilizados; selecionaram-se as 23 referências mais citadas. Quanto à metodologia de pesquisa verificou-se a predominância do uso da metodologia qualitativa $(58,7 \%$ do total). Os artigos focalizaram dez temáticas principais, sendo as três mais frequentes: (i) Criação de Novos Negócios; (ii) Ensino e Aprendizagem; (iii) Intra-empreendedorismo. Entende-se que os resultados possibilitam reflexões acerca do futuro da temática do empreendedorismo no país.
\end{abstract}

Palavras-chave: Empreendedorismo; Bibliometria; Produção Acadêmica; Eventos da ANPAD.

\begin{abstract}
This paper aims to analyze Brazil's academic production on entrepreneurship with a specific focus on the papers resulting from the framework of the following ANPAD-sponsored events from 2001 to 2012: EMA, EnEO, Symposium, EnEPQ, $3 E$, EnGPR, EnAPG and EnANPAD. These events see the country's top entrepreneurship researchers raising issues and sharing their interests, which make them ideal for gaining a privileged understanding of the themes latest news and relevant trends. An exploratory study approach was taken, qualitative as to the nature of the literature and using content analysis and quantitative for the corresponding descriptive statistics. A total of 150 papers containing the term "entrepreneurship" in the title were located by ANPAD's electronic search system and subsequently analyzed. After the analysis of the 5,251 references used in the papers, it was found that there were 22 authors who appeared frequently and the 23 most cited references were identified. The findings also show a predominance of qualitative methodologies (58.7\% of the total). The papers focused on 10 main themes, with the three most common being: (i)Starting New Businesses; (ii) Teaching and Learning; (iii) Intrapreneurship. It is understood that the results allow for reflections on the theme of the future of entrepreneurship in Brazil. Keywords: entrepreneurship; bibliometrics; academic production; ANPAD events.
\end{abstract}




\section{INTRODUÇÃO}

O empreendedorismo tem se destacado como temática de trabalhos em diferentes ambientes acadêmicos ou mesmo de caráter profissional. Há os que têm se dedicado a entender o conceito por intermédio de teorias consagradas da Economia, Sociologia, Teoria das Organizações, entre outras, assim como aqueles que têm se esforçado a analisar o fenômeno sob o prisma empírico, ou seja, a partir de observações, questionamentos e compreensões sobre as práticas empreendedoras que ocorrem ao nosso redor.

Muito embora se reconheça que exista um debate em construção nesta temática, deve-se reconhecer que se trata de um assunto que vem conquistando espaço na agenda de diversos pesquisadores e até mesmo de profissionais dedicados à criação de novas empresas, produtos ou serviços em distintos contextos e ambientes organizacionais. Além disso, parece haver uma busca, pelos pesquisadores, por um caminho teórico mais sólido e robusto.

As principais discussões acerca do empreendedorismo datam dos séculos xviII com Richard Cantillon (2002) com seu livro sobre "Ensaio sobre a Natureza do Comércio em Geral" e xIx a partir dos trabalhos do economista Jean-Baptiste Say (1964) no qual conceituou o empreendedor como aquele que é capaz de transferir recursos financeiros para um setor com melhor retorno e produtividade. Entretanto, foi com outro economista, Joseph Schumpeter (1934), que o tema do empreendedorismo ganha uma dimensão mais ampla. Este autor destacou o papel inovador que os empreendedores protagonizam por meio de um processo criativo-destrutivo na oferta de novos produtos e serviços no contexto do sistema capitalista.

Desde então, diversos profissionais e pesquisadores têm-se se dedicado a compreender o fenômeno do empreendedorismo, as suas relações com a Economia e a sociedade, assim como na dinâmica das organizações. Em diferentes contextos, setores público (empreendedorismo público), privado (novos negócios) e sociedade civil (empreendedorismo social), acompanham-se o surgimento de iniciativas empreendedoras, inclusive no próprio ambiente organizacional (intra-empreendedorismo). Diante disso, 
este estudo será orientado pelas seguintes questões de pesquisa: a) quais as características da produção científica sobre empreendedorismo apresentada nos eventos da ANPAD? e b) quais os principais autores, bibliografias e temas tratados pelos pesquisadores? Acredita-se que fazer um balanço do que foi produzido sobre empreendedorismo é algo necessário e, principalmente, útil em futuras pesquisas e publicações nessa temática.

É relevante observar que a análise bibliométrica de estudos científicos é oportuna para a comunidade acadêmica, pois: a) indica a novos pesquisadores os temas já tratados; b) verifica inconsistências na pesquisa realizada, tais como necessidades de estudos qualitativos ou quantitativos e c) permite identificar lacunas na teoria existente (COOPER; LINDSAY, I998). Ademais, reconhecem-se as bibliografias relevantes para estudos futuros, assim como observar as instituições que têm apresentado uma produção científica.

Dessa forma, ao tentar responder as questões de pesquisa, busca-se ampliar as oportunidades para que outros pesquisadores possam agregar em suas agendas de pesquisa temas que ainda não foram suficientemente abordados ou ainda aprofundem-se nas temáticas que já foram tratadas, repensem e até mesmo aperfeiçoem suas temáticas, atualizem-se quanto às bibliografias mais relevantes sobre empreendedorismo e, principalmente, que os interessados na temática façam reflexões sobre as suas potenciais contribuições no âmbito acadêmico.

Para cumprir com os objetivos deste artigo, além desta introdução, ele foi estruturado da seguinte forma: apresentar uma breve contextualização sobre o empreendedorismo; em seguida, busca-se discutir a produção científica em empreendedorismo; na sequência, apresenta-se a metodologia de pesquisa bibliométrica com base nos procedimentos de coleta de dados e, em seguida, parte-se para a discussão sobre os resultados. Finalmente, são apresentadas as considerações finais e as referências utilizadas na pesquisa. 


\section{BREVE CONTEXTUALIZAÇÃO SOBRE O CAMPO DO EMPREENDEDORISMO}

A temática do empreendedorismo é recente no Brasil. O primeiro Encontro de Estudos sobre Empreendedorismo e Gestão de Pequenas Empresas (EGEPE) foi realizado em 2000 . Foi em 2003 que se lançou para este assunto no contexto do Encontro da Associação Nacional de Pós-Graduação e Pesquisa em Administração (ENANPAD). Além disso, diversos pesquisadores ressalvam que não se desenvolveu uma teoria específica sobre o empreendedorismo (GREBEL; PYKA; HANUSCH, 2003; AMIT; GLOSTEN; MULLER, I993; BYGRAVE; HOFER, I99I).

Os trabalhos iniciais sobre empreendedorismo destacavam, sobretudo, a criação de produtos e serviços ou mesmo empresas de caráter privado, privilegiando o aspecto econômico relacionado ao empreendedorismo. Atualmente, as pesquisas nessa temática contemplam, além das empresas privadas, iniciativas promovidas no âmbito do setor público e da sociedade civil. Além disso, outros aspectos emergem como relevantes no campo do empreendedorismo, tais como aspectos relacionados ao gênero e as distinções quanto ao estilo de gestão das mulheres (QUENTAL; WETZEL, 2002; GOMES; SANTANA; ARAÚJO, 2009; GOMES; GUERRA; VIEIRA, 2OII) e à religião e suas influências sobre o comportamento empreendedor e os negócios (FREITAS; RIBEIRO; LOBO; LIMA; PEÑALOZA, 2008; SERAFIM; MARTES; RODRIGUEZ, 20IO).

Outras possibilidades de pesquisas e perspectivas de análise têm emergido entre os pesquisadores brasileiros, tais como o ensino e aprendizado de empreendedorismo (HENRIQUE; CUNHA, 2006; PAIVA; ALMEIDA; OLIVEIRA, 2007; LIMA; LOPES; NASSIF, 2OI2) e construção do discurso, aspectos epistemológicos e abordagem teórica (CORDEIRO; MELLO, 2006; BOAVA; MACEDO, 2006; NASSIF; SILVA; ONO; BONTEMPO, TINOCO, 2009) e empreendedorismo regional e micro, pequenos e médios negócios (FREITAG; AMAL, 2008; PEREIRA; CORDEIRO; SILVA, BATISTA, 20I2).

Neste contexto, acredita-se que os esforços no sentido de levantar, sistematizar e analisar as produções acadêmicas nos eventos promovidos pela ANPAD, no sentido de aperfeiçoar a compreensão teórica e empírica sobre o empreendedorismo é algo legítimo e relevante. 


\section{A PRODUÇÃO ACADÊMICA SOBRE EMPREENDEDORISMO}

Levantemos acerca de produção científica é uma prática presente em diferentes temáticas na área de gestão. Com relação à temática do terceiro setor, por exemplo, Iizuka e Sano (2004) e Paula, Olivero, Muritiba e Muritiba (20I0) realizaram as suas investigações, respectivamente, nos anais do ENANPAD e em periódicos de alto impacto brasileiros. Bertero, Caldas e Wood (2005), por sua vez, analisaram a produção acadêmica na área de estudos organizacionais. Os estudos sobre estratégia foram objetos de pesquisa de Bertero, Vasconcelos e Binder (2003). No campo da gestão pública no Brasil, Keinert (2000) buscou caracterizar os paradigmas da administração pública no Brasil, em função do conceito de público, analisando os artigos publicados entre 1937 e 1997 na Revista de Administração Pública (RAP) e na Revista do Serviço Público (RSP).

Em específico, no campo do empreendedorismo, foram encontrados quatro artigos com o caráter bibliométrico no âmbito dos encontros promovidos pela ANPAD. O primeiro foi publicado por Paiva e Cordeiro (2002) tratou da produção acadêmica entre 1998 e 200I no qual se verificou a predominância de assuntos relativos ao comportamento estratégico das empresas e dos indivíduos. O segundo artigo foi apresentado no ENANPAD de 2007 e foi desenvolvido por Cassol, Silveira e Hoeltgebaum (2007) e tratou da produção científica relativo ao empreendedorismo feminino entre 1996 e 2006; as autores verificaram que as dimensões individual e ambiente se apresentaram como mais frequentes.

O terceiro artigo foi escrito por Nassif et al. (2009) sobre a produção acadêmica entre os anos de $200 \mathrm{r}$ e 2008; os autores verificaram que os artigos tinham uma base funcionalista e que os temas de maior interesse são o comportamento, atitude, perfil e competências do empreendedor. $\mathrm{O}$ quarto artigo foi apresentado por Silveira, Ropelato e Nascimento (2010) e tratou das publicações da base Scielo entre 2004 e 2008 e as autoras chegaram ao seguinte resultado: Schumpeter, Cantillon, Shane e Venkataraman, Hisrich e Peters foram os autores mais utilizados nos ig artigos analisados; inovação e redes surgiram como termos frequentes e, finalmente, houve um predomínio de organizações de caráter público. 
\& OUTROS

Analisando-se os quatro artigos citados, em nenhum deles se observou uma análise mais detalhada das referências utilizadas. Além disso, parece haver outras temáticas de pesquisa que não foram devidamente explicitadas nos trabalhos anteriores. Dessa forma, a pesquisa desenvolvida pode ser compreendida como um esforço adicional em sistematizar a produção na temática do empreendedorismo. 


\section{CONDUÇÃO DA PESQUISA}

No momento inicial da pesquisa, planejou-se selecionar os periódicos de alto impacto na área de Administração para a realização de um levantamento da produção acadêmica relacionada ao empreendedorismo. Como potencial fonte para o desenvolvimento da pesquisa pensou-se nos seguintes periódicos: RAP, Revista de Administração Pública da FGv; O\&S, Organizações e Sociedade da UfBA; RAE, Revista de Administração de Empresas da FGv, RAUSP, Revista de Administração da uSP e a RAC, Revista de Administração Contemporânea da ANPAD, entre outros.

Devido à limitação de tempo e recursos, foi decidido focalizar, nesta pesquisa, os anais dos eventos promovidos pela ANPAD, referentes ao período compreendido entre 2001e 2012. Vale observar que boa parte dos artigos apresentados nos eventos acadêmicos da ANPAD foram frutos das dissertações e teses desenvolvidas nas principais Instituições de Ensino brasileiras e parte dos trabalhos aprovados nesse evento científico é encaminhado aos periódicos. Assim, considera-se que a base de artigos dos eventos da ANPAD é relevante e adequada para os objetivos propostos neste trabalho.

$\mathrm{Na}$ sequência, foi realizado um levantamento dos artigos via internet, especificamente o sistema de busca de artigos do site da ANPAD. Ao todo, foram encontrados 153 artigos que tinham como temática principal o empreendedorismo. Todos os artigos tinham o termo "empreendedorismo" no título, o que indicava o foco principal do trabalho. Por problemas técnicos do sistema de busca, três artigos foram descartados, pois não correspondiam ao foco da pesquisa. Procedeu-se, então, a leitura de cada um deles e dessa forma montou-se um banco de dados com as principais informações colhidas com base nos 150 artigos considerados válidos.

Cabe observar que a delimitação dos artigos selecionados para a análise foram os que apresentaram o empreendedorismo no título do trabalho, ou seja, foram excluídos os artigos que mencionaram o assunto apenas como parte acessória à temática principal ou mesmo em algum argumento específico. Fez-se este tipo de escolha, pois, em geral, é com base no título que os autores definem os conteúdos mais relevantes a serem apresentados ao longo do artigo. 
A sistematização dos dados e informações dos artigos selecionados permitiu, entre outras coisas, a verificação dos seguintes itens: o número de artigos sobre empreendedorismo ao longo dos anos; o referencial bibliográfico utilizado; as obras mais utilizadas pelos autores dos artigos; os autores que tiveram um maior número de menções nos trabalhos; a origem em termos institucionais dos artigos, assim como geográficos; as temáticas mais presentes nos artigos analisados e, finalmente, o tipo de metodologia de pesquisa utilizado.

Portanto, a estratégia utilizada foi a pesquisa documental, de caráter exploratório, de cunho misto (quali-quanti), onde foram analisados os artigos referentes à temática do empreendedorismo nos eventos promovidos pela ANPAD, ou seja: EMA, ENEO, Simpósio, ENEPQ, 3 Es, ENGPR, ENAPG E ENANPAD. Moreira (2005) salienta que a pesquisa documental caracteriza-se como processo de levantamento, verificação e interpretação de documentos, tendo como objetivo um fim predeterminado que, conforme observam Marconi e Lakatos (1990), pode ser efetuada ao longo dos anos, pois as informações estarão arquivadas nos referidos documentos.

Finalmente, após a leitura e sistematização das informações dos artigos, utilizou-se a estatística descritiva simples dos artigos de acordo com as variáveis: artigos em que o título revelava foco na temática do empreendedorismo; instituição de ensino do autor principal; autoria; localização geográfica e método utilizado. 


\section{APRESENTAÇÃO E ANÁLISE DOS RESULTADOS}

Considerando-se os doze anos dos eventos da ANPAD, foi localizado um total de $\mathrm{I} 50$ artigos válidos e de acordo com os objetivos propostos nesta pesquisa. Na Tabela I apresenta-se a evolução dos artigos sobre empreendedorismo:

Tabela I Quantidade de Artigos Apresentados nos Eventos da ANPAD entre 200I e 2012

\begin{tabular}{|llllll|}
\hline Ano & Quantidade & $\%$ Total & Ano & Quantidade & $\%$ Total \\
\hline 2001 & 2 & $1,3 \%$ & 2007 & 20 & $13,3 \%$ \\
\hline 2002 & 3 & $2 \%$ & 2008 & 27 & $18 \%$ \\
\hline 2003 & 7 & $4,7 \%$ & 2009 & 16 & $10,7 \%$ \\
\hline 2004 & 12 & $8 \%$ & 2010 & 17 & $11,3 \%$ \\
\hline 2005 & 6 & $4 \%$ & 2011 & 7 & $4,7 \%$ \\
\hline 2006 & 18 & $12 \%$ & 2012 & 15 & $10 \%$ \\
\hline Total & $\mathbf{4 8}$ & $\mathbf{3 2 \%}$ & Total & $\mathbf{1 0 2}$ & $\mathbf{6 8 \%}$ \\
\hline
\end{tabular}

A distribuição dos artigos pelos eventos promovidos pela ANPAD, ou seja, EMA, ENEO, Simpósio, ENEPQ, 3 Es, ENGPR, ENAPG e ENANPAD, conforme apresentado na Tabela 2:

Tabela 2 Distribuição dos Artigos nos Eventos da ANPAD entre 200 I e 2012

\begin{tabular}{|c|c|c|c|c|c|c|c|c|c|c|c|c|}
\hline Eventos & 2001 & 2002 & 2003 & 2004 & 2005 & 2006 & 2007 & 2008 & 2009 & 2010 & 2011 & 2012 \\
\hline EnANPAD & 2 & 3 & 6 & 10 & 5 & 9 & 12 & 10 & 13 & 11 & 7 & 14 \\
\hline $3 \mathrm{Es}$ & & & 1 & & 1 & & & & 1 & & & \\
\hline EMA & & & & & & 1 & & & & & & \\
\hline EnAPG & & & & 1 & & 2 & & & & 1 & & \\
\hline EnEO & & & & 1 & & & & 2 & & 3 & & \\
\hline EnEPQ & & & & & & & 8 & & 1 & & & \\
\hline EnGPR & & & & & & & & & 1 & & & \\
\hline Simpósio & & & & & & 6 & & 15 & & 2 & & 1 \\
\hline TOTAL & 2 & 3 & 7 & 12 & 6 & 18 & 20 & 27 & 16 & 17 & 7 & 15 \\
\hline
\end{tabular}

Fonte: Elaborado pelos Autores com base nos Anais dos eventos da ANPAD (2001 a 2012). 
Em relação à autoria das pesquisas, houve um predomínio de autores que apresentaram em dupla os seus trabalhos (44\%) e, em seguida, a presença de três autores foi observada em $26 \%$ dos artigos analisados. Num outro extremo, trabalhos com seis autores ocorreram em $2 \%$ dos artigos, ou seja, em termos absolutos quatro pesquisas, conforme consta na Tabela 3:

Tabela 3 Distribuição dos artigos por número de autores dos anais dos eventos da Anpad (200I a 2012)

\begin{tabular}{|lll|}
\hline No. Autores & Quantidade & $\%$ \\
\hline 1 & 19 & $12,7 \%$ \\
\hline 2 & 66 & $44 \%$ \\
\hline 3 & 39 & $26 \%$ \\
\hline 4 & 17 & $11,3 \%$ \\
\hline 5 & 6 & $4 \%$ \\
\hline 6 & 3 & $2 \%$ \\
\hline
\end{tabular}

Fonte: Elaborado pelos Autores com base nos Anais dos eventos da ANPAD (2001 a 2012).

A predominância de artigos com dois ou três autores parece apontar para um quadro em que a produção científica, no contexto dos eventos dos ENANPADs, tem ocorrido, sobretudo, por meio de esforços coletivos, provavelmente respaldos por equipes de pesquisa. Em contrapartida, os trabalhos com um autor (em torno de $12 \%$ ) podem significar que parte dos pesquisadores está trabalhando por meio de esforços individuais e dissociados das equipes de pesquisa e centros de estudo.

Analisando-se a produção científica e as Instituições de Ensino Superior - IES de origem, foi possível perceber uma quantidade considerável de universidades e faculdades -58 IES nos 12 anos de eventos da ANPAD. É preciso considerar a concentração dos artigos entre as I5 IES que mais apresentaram artigos: 76 trabalhos, ou seja, $51 \%$ do total.

Tal resultado é coerente ao que era esperado, pois nestas IES existe a presença de pesquisadores focados nesta temática e, em algumas delas, há a presença de centros de estudos e pesquisas, tal como o a Diretoria de Inovação e Empreendedorismo da UFPE, Incubadora de Empresas da UFLA 
e o Centro de Estudos de Empreendedorismo e Novos Negócios da GV, o GVCENN da FGV-EAESP. A Tabela 4 apresenta as I5 IEs brasileiras com o maior número de artigos entre 200I e 20I2:

Tabela 4 As I5 Instituições de Ensino Superior com maior número de artigos entre 2001 e 2012

\begin{tabular}{|llll|}
\hline IES & Quantidade & IES & Quantidade \\
\hline UFPE & 10 & UECE & 4 \\
\hline UFLA & 6 & PUC-MG & 4 \\
\hline UFPR & 6 & UEL & 4 \\
\hline FGV-EAESP & 6 & UEM & 4 \\
\hline UNIFOR & 5 & UFRJ & 4 \\
\hline Universidade Positivo & 5 & PUC-RJ & 4 \\
\hline UFRGS & 5 & ESAG/UDESC & 4 \\
\hline FURB & 5 & & \\
\hline
\end{tabular}

Fonte: Elaborado pelos Autores com base nos Anais dos eventos da ANPAD (2001 a 2012).

Por outro lado, a diversidade de IES pode indicar, entre outros, que o empreendedorismo tem emergido como temática nestas instituições de ensino, assim como parece apontar para uma área que se encontra disseminada, porém em construção no país. Com relação aos Estados e Regiões brasileiras, os resultados obtidos apontaram uma predominância da produção científica em oito Estados da federação, quais sejam: PR, MG, SP, RJ, SC, RS, CE e PE, com 92,6\% do total. Para chegar a esses resultados, foram consultados os currículos lattes dos primeiros autores dos artigos e as IES ao qual estavam vinculados no ano da apresentação do trabalho nos eventos da ANPAD, conforme apresentado na Tabela 5. 
Tabela 5 Distribuição dos artigos por Estado

\begin{tabular}{|lll|lll|}
\hline Estado & Quantidade & $\%$ & Estado & Quantidade & $\%$ \\
\hline PR & 29 & $19,5 \%$ & AL & 3 & $2 \%$ \\
\hline MG & 26 & $17,4 \%$ & DF & 3 & $2 \%$ \\
\hline SP & 18 & $12,1 \%$ & SE & 2 & $1,3 \%$ \\
\hline RJ & 17 & $11,4 \%$ & BA & 1 & $0,7 \%$ \\
\hline SC & 14 & $9,4 \%$ & GO & 1 & $0,7 \%$ \\
\hline RS & 13 & $8,7 \%$ & PB & 1 & $0,7 \%$ \\
\hline CE & 11 & $7,4 \%$ & & & \\
\hline PE & 10 & $6,7 \%$ & & & \\
\hline
\end{tabular}

Fonte: Elaborado pelos Autores com base nos Anais dos eventos da ANPAD (2001 a 2012).

Em uma segunda sistematização da regionalidade, foi possível constatar que a produção científica sobre empreendedorismo nos eventos da ANPAD se concentra nas regiões sudeste (40,9\%) e sul (37,6\%). A região centro-oeste teve apenas $2,7 \%$ dos trabalhos e a região norte, por sua vez, não apresentou nenhum artigo ao longo do período analisado. Ou seja, a pesquisa sobre a produção científica em empreendedorismo com base nos eventos da ANPAD revelou um quadro de desequilíbrio sob a ótica geográfica.

A pesquisa apontou um predomínio do uso das metodologias qualitativas nos artigos apresentados nos eventos da $\operatorname{ANPAD}(58,7 \%)$. A sistematização das bibliografias, com base na revisão bibliográfica, as análises de experiências e projetos por meio de estudos de caso, análise de discurso, se apresentaram como as principais técnicas qualitativas. Além disso, se destacou a presença de ensaios teóricos ( $14,7 \%)$, algo que indica, provavelmente, uma área científica que está em construção. Com relação aos métodos quantitativos (i8\%), foi possível observar testes estatísticos de hipóteses, análises de regressão, equações estruturais e a análise de redes. A Tabela 6 sintetiza as informações apresentadas: 
Tabela 6 Tipos de metodologias de pesquisa adotadas nos artigos

\begin{tabular}{|lll|}
\hline Metodologias & Quantidade & $\%$ \\
\hline Quantitativa & 27 & $18 \%$ \\
\hline Qualitativa & 88 & $58,7 \%$ \\
\hline Mista & 13 & $8,7 \%$ \\
\hline Ensaio Teórico & 22 & $14,7 \%$ \\
\hline
\end{tabular}

Fonte: Elaborado pelos Autores com base nos Anais dos eventos da ANPAD (2001 a 2012).

A investigação dos artigos incluiu as temáticas que os autores apresentaram ao longo dos doze anos de eventos da ANPAD. Num esforço de síntese, perceberam-se dez temáticas principais: (I) Criação de Novos Negócios; (II) Ensino e Aprendizagem; (III) Intra-empreendedorismo; (IV) Abordagem Teórica e Construção do Discurso; (v) Empreendedorismo Social e Ambiental, (vi) Micro e Pequenas Empresas e Contextos Regionais, (viI) Redes de Relacionamento e Capital Social, (viII) Empreendedorismo Feminino e aspectos relacionados ao Gênero, (Ix) Crescimento Econômico e Aspectos Históricos e, finalmente, (x) Influência Religiosa e Religião.

Essas temáticas parecem indicar quais são os assuntos mais relevantes, neste momento, no campo do empreendedorismo no Brasil. Isso não exclui outras possibilidades de pesquisa, apenas aponta as temáticas sobre as quais os pesquisadores que apresentaram artigos nos eventos da ANPAD têm empreendido seus esforços. A Tabela 7 apresenta as temáticas e subtemas percebidos dos artigos analisados. 
Tabela 7 Os temas de empreendedorismo mais relevantes nos artigos analisados

Temas e Quantidade de Artigos

I. Criação de Novos Negócios e Outros Temas

(24 artigos)

II. Educação, Ensino, Aprendizagem, Universidade

(23 artigos)

III. Intra-empreendedorismo, Empreendedorismo Interno (2I artigos)

IV. Abordagem Teórica, Construção do Discurso, Epistemologia, Construção do Sentido (I7 artigos)

V. Empreendedorismo Social, Empreendedorismo Sustentável, Negócios Sociais (I7 artigos)

VI. Empreendedorismo em Contextos específicos, Micro e Pequenas Empresas, Empreendedorismo Regional (I6 artigos)

VII. Redes de Relacionamento, Capital Social, Competências, Teoria do AtorLiderança, Cooperação entre Governo, Empresas e Universidades, Associações Comerciais

Rede (I2 artigos)

VIII. Empreendedorismo Feminino, Empreendedorismo por Gênero (Io artigos)

IX. Crescimento Econômico, Aspectos Históricos e Culturais (6 artigos)

X. Influência Religiosa, Religião Cidades Religiosas, Capital Espiritual (4 artigos)

\section{Subtemas}

Tolerância ao Risco, Empresas Incubadas, Incubadoras, Percepção sobre Inovação, Criatividade, Estratégia, Internacionalização

Empresas criadas por professores; Interação Universidade-Empresa; Metodologia de Vida, Educação Básica, Escolas EUA

\section{Gênero, Cultura Organizacional, Estratégia,} Estrutura, Valores, Clima Organizacional.

Produção Científica, Sentido Axiológico, Teorias Organizacionais, Dimensão Filosófica

Arranjos Produtivos Locais; Gênero; Terceiro Setor; Base da Pirâmide

Chineses, Empreendedorismo Público, Área da Saúde, Setor Alimentício, Software, Internacionalização
Conflito trabalho-família, Qualidade de Vida, Estilo gerencial, Homossexualidade, Produção científica.
Tributação, BRICs, Comparação entre Países 
Na temática “Criação de Novos Negócios e outros temas” encontraram-se artigos, tais como "A Influência da Percepção sobre Inovação, Criatividade, Aprendizagem e Empreendedorismo na Avaliação de Casas Noturnas” escrito por André Luís Janzkovski Cardoso, Suziméri Vilas Boas Pescador e Carlos Olavo Quandt da PUC-PR E "Empreendedorismo Internacional: Proposição de um Framework” de Yákara Vasconcelos Pereira Leite e Walter Fernando Araújo de Moraes da UfPE e "As Incubadoras como Ambientes de Aprendizagem do Empreendedorismo” elaborado por Nathalia Fiala da FGV-EAESP. Os três artigos foram apresentados no ENANPAD, 20I2, os quais apontam os caminhos recentes trilhados pelos pesquisadores da área de empreendedorismo.

A atenção em relação à temática de Educação, Ensino e Aprendizagem e Universidade, foi percebida em artigos como "Metodologias, Recursos e Práticas Didático-Pedagógicas no Ensino de Empreendedorismo em Cursos de Graduação e Pós-Graduação Nacionais e Internacionais” elaborado por Daniel Christian Henrique e Sieglinde Kindl da Cunha da UFPr e apresentado no ENANPAD de 2006; "Perspectivas para a Formação Orientada para o Empreendedorismo: Uma Experiência Dialógica de Ensino no Curso de Graduação em Administração” dos autores Fernando Gomes de Paiva Júnior, Larissa Fernanda de Lima Almeida e Marcos André Farias de Oliveira da UFPE e divulgado no ENEPQ de 2007 e "Empreendedorismo para Todos: Desafios e Oportunidades para Aperfeiçoar a Educação Superior Brasileira” elaborado por Edmilson Lima, Rose Mary Almeida Lopes, Vânia Maria Jorge Nassif da UNINOVE e exposto no ENANPAD de 20I2. Trata-se de uma temática atual e com espaço para novas pesquisas.

Outra temática associada ao empreendedorismo que se apresentou como relevante foi o do "Intra-empreendedorismo e empreendedorismo interno". Os artigos que ilustram essa temática: "Relações entre Intraempreendedorismo, Clima Organizacional e Desempenho Financeiro Um Estudo sobre as Melhores Empresas para se Trabalhar no Brasil” dos autores Marcos Hashimoto, Tales Andreassi, Rinaldo Artes e Lina Eiko Nakata da FACAMP e divulgado no ENANPAD, 20IO; "Intraempreendedorismo Feminino, Competências Empreendedoras e Conflito Trabalho-Família: 
Um Estudo de Caso com Professoras de Programas de Mestrado e Doutorado em Administração de Curitiba-PR" escrito por Marcia Aparecida Zampier e Adriana Roseli Wünsch Takahashi da UNICENTRO - PR e "Empreendedorismo em Empresas Familiares: Intraempreendedorismo e Famílias Empreendedoras" de Juvêncio Braga de Lima, Kelly Lopes Silva e Daniel Ribeiro Conde da ufla. Os dois últimos artigos foram apresentados no EnEO de 20Io. Os exemplos citados colaboram para os pesquisadores interessados na temática do intra-empreendedorismo.

Neste contexto, os artigos que tratam da "Abordagem Teórica, Construção do Discurso, Epistemologia, Construção do Sentido" se apresentaram em número considerável. Exemplificam esse tipo de artigo: "Rupturas, Permanências e Ressignificações na Estrutura Discursiva do Empreendedorismo" desenvolvido por Adriana Tenório Cordeiro e Sérgio C. Benício de Mello da UfPE, aprovado no EnANPAD de 2006; "Constituição Ontoteleológica do Empreendedorismo" de autoria de Diego Luiz Teixeira Boava e Fernanda Maria Felício Macedo da ufPR e apresentado no ENANPAD de 2007 e "Empreendedorismo: Área em Evolução? Uma Revisão dos Estudos e Artigos Publicados entre 200r e 2008" dos pesquisadores Nassif et al. do Mackenzie-SP e divulgado no ENANPAD de 2009. Trata-se de trabalhos que buscam construir o conceito (ou mesmo a teoria) do empreendedorismo. Dado que ainda não existe uma teoria a respeito, novos trabalhos nessa perspectiva são necessários.

A temática "Empreendedorismo Social,EmpreendedorismoSustentável, Negócios Sociais" foi um dos temas mais frequentes entre os diversos artigos analisados. Entre eles citam-se: "Empreendedorismo Sustentável: Proposição de uma Tipologia e Sugestões de Pesquisa” elaborado por Borges, Borges, Ferreira, Najberg, e Tete da Universidade Federal de Goiás e exposto no EnANPAD de 20II; "O Empreendedorismo Sustentável e o Processo Empreendedor: Em Busca de Oportunidades de Novos Negócios como Solução para Problemas Sociais e Ambientais" das autoras Anna Karina Boschzowski e Rivanda Teixeira da UfPR e apresentado no ENANPAD de 2009; "Empreendedorismo Social: um Estudo da Relação entre os Elementos Constituintes do Empreendedorismo e a Gestão de Organizações Sociais" 
dos pesquisadores Antônio dos Santos Silva e Henrique Cordeiro Martins da Universidade FUMEC - MG e divulgado no ENANPAD, 20IO. De fato, novas organizações têm emergido da sociedade (por exemplo: empresas com impactos sociais e financeiros) e esta, por sua vez, tem demandado novos produtos e serviços num contexto de desenvolvimento sustentável. Ou seja, há claro potencial de pesquisa nessa temática.

Como sexto tema mais frequente verificou-se o "Empreendedorismo em Contextos específicos, Micro e Pequenas Empresas, Empreendedorismo Regional". Apresentam-se dois artigos que exemplificam essa temática: "Estratégias e Determinantes da Internacionalização de Pequenas e Médias Empresas (pmes): Abordagem da Teoria de Redes de Relacionamento e Empreendedorismo" elaborado por Alexandre Rocha Freitag Filho e Mohamed Amal da Universidade Regional de Blumenau e exposto no ENANPAD de 2008; "Empreendedorismo Regional: Um Olhar sobre a Identidade Cultural em Narrativas Locais" dos autores Pereira et al. da UFPE e apresentado no ENANPAD de 20I2. O Brasil é um país com distintas realidades sociais, econômicas e culturais e tal perspectiva de estudo no campo do empreendedorismo é, de fato, promissor.

Em seguida, verificou-se a temática "Redes de Relacionamento, Capital Social, Competências, Teoria do Ator-Rede" e dois artigos são exemplos dessa perspectiva: "Empreendedorismo e Redes: a exploração de oportunidades em Associações Comerciais” de Hilka Vier Machado, Tayso Silva e Maurício Reinert do Nascimento da UEm e apresentado no ENANPAD de 2009; "Empreendedorismo pela Ótica da Teoria Ator-Rede: Explorando Alternativa às Perspectivas Subjetivista e Objetivista" elaborado por Dany Flávio Tonelli, Mozar José de Brito e André Luiz Zambalde da unifal e exposto no Simpósio de 20I0. Numa sociedade cada vez mais complexa e, ao mesmo tempo, interconectada, a questão das redes e do capital social parece ser relevante ao campo do empreendedorismo.

A oitava temática verificada nos artigos foi "Empreendedorismo Feminino, Empreendedorismo por Gênero" tal recorte teórico pode ser visto nos artigos: "Empreendedorismo Feminino: o estado-da-arte" escrito por Almiralva Ferraz Gomes, Weslei Gusmão Piaue Santanta e Uajará Pessoa 
Araújo da UfLa e divulgado no ENANPAD de 2009; um outro trabalho foi "O Desafio do Empreendedorismo Feminino" elaborado por Daniel Teodoro Gomes, Paulo Vítor Guerra e Bruna Nobre Vieira da UfMg e apresentado no ENANPAD de 20II. Acredita-se que tal perspectiva de investigação seja relevante, atual e necessária, pois o mercado e a própria sociedade carecem de estudos que analisem aspectos relacionados ao gênero.

Num próximo passo foi possível constatar a temática do "Crescimento Econômico, Aspectos Históricos e Culturais" e o artigo sobre "Empreendedorismo, Crescimento Econômico e Competividade dos BRIcs: Uma Análise Empírica a partir dos Dados do GEM e GCI” elaborado por Raimundo Eduardo Silveira Fontenele, Paulo Francisco Barbosa Sousa e Alexandre Oliveira Lima da UNIFOR e relatado no ENANPAD de 201 ilustra tal possibilidade de pesquisa. Finalmente, a temática "Influência Religiosa, Religião” tem chamado a atenção de um conjunto de pesquisadores brasileiros. O artigo "Segurando na Mão de Deus: Organizações Religiosas e Estruturas de Suporte ao Empreendedorismo" escrito por Mauricio C. Serafim, Ana Cristina Braga Martes e Carlos L. Rodriguez da UDESC e exposto no enANPAD de 20 o é um bom exemplo nesse sentido. Diante dessas duas últimas temáticas, e considerando-se o contexto brasileiro, parece haver um campo ainda fértil a ser explorado pelos pesquisadores.

Após percorrer as principais temáticas sistematizadas com base nos artigos expostos nos eventos da ANPAD, apresentam-se as análises sobre os autores mais citados nos trabalhos, assim como as obras que foram mencionadas mais vezes nos artigos pesquisados. A Tabela 8 apresenta os autores mais citados nos 150 artigos utilizados na investigação.

Tabela 8 Os autores mais citados

\begin{tabular}{|c|c|c|c|}
\hline 22 Autores mais Citados & $\begin{array}{l}\text { Número de } \\
\text { Citaçōes }\end{array}$ & 22 Autores mais Citados & $\begin{array}{l}\text { Número de } \\
\text { Citações }\end{array}$ \\
\hline FILION, L. J. & 107 & HISRICH, R. D. & 22 \\
\hline SCHUMPETER, J. A. & 81 & COVIN, J. G. & 21 \\
\hline DOLABELA, F. (BR) & 46 & ALDRICH, Howard & 20 \\
\hline DRUCKER, P. F. & 46 & CARLAND, J. W. & 19 \\
\hline
\end{tabular}




\begin{tabular}{|c|c|c|c|}
\hline 22 Autores mais Citados & $\begin{array}{l}\text { Número de } \\
\text { Citaçōes }\end{array}$ & 22 Autores mais Citados & $\begin{array}{l}\text { Número de } \\
\text { Citações }\end{array}$ \\
\hline DORNELAS, J. C. A . (BR) & 45 & STEVENSON, H. H. & 19 \\
\hline PAIVA Jr, F. G. (BR) & 37 & BARNEY, Jay B. & 17 \\
\hline McCLELLAND, D. C. & 35 & BYGRAVE, W. D. & 17 \\
\hline SHANE, S. & 31 & ZAHRA, S. A. & 17 \\
\hline GARTNER, W. B. & 30 & DEGEN, R. J. & 16 \\
\hline MACHADO, H. P. V. (BR) & 26 & KURATKO, D. F. & 16 \\
\hline PINCHOT, G. & 23 & MORRIS, M. H. & 16 \\
\hline
\end{tabular}

Fonte: Elaborado pelos Autores com base nos Anais dos eventos da ANPAD (2001 a 2012).

Cabe observar que na pesquisa bibliométrica desenvolvida por Silveira, Ropelato e Nascimento (2010) foi constatado que Schumpeter, Cantillon, Shane e Venkataraman, Hisrich e Peters foram os autores mais citados nos artigos da base Scielo sobre empreendedorismo entre 2004 e 2008. De fato, parte dos autores está na tabela anterior; se a base contemplasse os 40 autores mais citados, os seis autores estariam presentes na pesquisa que ora apresentamos. Dentre os vinte e dois autores mais citados, quatro deles são brasileiros: Dolabela, Dornelas, Paiva Jr. e Machado. A análise detalhada das 5.25I referências utilizadas nos 150 artigos apresentados nos eventos da ANPAD entre 200I e 20I2, possibilitou uma base mais ampla de investigação e isso, provavelmente, permitiu um conjunto mais amplo e diversificado de autores-chave no campo do empreendedorismo.

Pode-se perceber que autores considerados clássicos, tais como Filion, Schumpeter, McClelland, Pinchot e Hisrich se misturaram a autores mais recentes, tais como Dolabela, Dornelas, Paiva Jr. e Machado. Seja como for, tais autores são relevantes, neste momento, aos pesquisadores em empreendedorismo no Brasil. Entretanto, isso não significa que outros autores possam ser incluídos em pesquisas futuras. Os artigos apresentados nos eventos da ANPAD foram úteis no sentido de se verificar, afinal, quem são os autores mais importantes aos pesquisadores atuantes na área do empreendedorismo.

Em relação às obras mais utilizadas, exigiu um esforço considerável de captação, sistematização e análise das 5.25I referências presentes nos 150 artigos 


\section{$\&$ OUTROS}

selecionados. Assim, foram observadas as obras que se apresentaram com maior frequência e chegou-se ao seguinte resultado sistematizado na Tabela 9:

Tabela 9 As referencias mais citadas

\begin{tabular}{|c|c|c|c|}
\hline & Obras mais Citadas & Autor(es) & Mençōes \\
\hline 1 & $\begin{array}{l}\text { Theory of economic development: an inquiry } \\
\text { into profits, capital, credit, interest and the } \\
\text { business cycle. Cambridge: Harvard University } \\
\text { Press, } 1934 .\end{array}$ & SCHUMPETER, J.A. & 74 \\
\hline 2 & $\begin{array}{l}\text { Empreendedorismo: empreendedores e } \\
\text { proprietários-gerentes de pequenos negócios. } \\
\text { Revista de Administração, v. 34, n.2, p. 5-28, } 1999 .\end{array}$ & FILLION, L. J. & 42 \\
\hline 3 & $\begin{array}{l}\text { Inovação e Espírito Empreendedor. São Paulo: } \\
\text { Pioneira. } 1987 .\end{array}$ & DRUCKER, P. F. & 31 \\
\hline 4 & $\begin{array}{l}\text { Empreendedorismo: transformando ideias em } \\
\text { negócios. Rio de Janeiro: Campus, } 2008 .\end{array}$ & DORNELAS, J. C. A. & 30 \\
\hline 5 & $\begin{array}{l}\text { Empreendedorismo. Porto Alegre: Bookman, } \\
2004 .\end{array}$ & HISRICH, R. D.; PETERS, M. P. & 19 \\
\hline 6 & $\begin{array}{l}\text { The promise of entrepreneurship as a field of } \\
\text { research. Academy of Management Review, v.25, } \\
\text { n.1, p.217-226, } 2000 \text {. }\end{array}$ & SHANE, S.; VENKATARAMAN, S. & 19 \\
\hline 7 & $\begin{array}{l}\text { Oficina do Empreendedor. São Paulo: Cultura } \\
\text { Editores, } 1999 .\end{array}$ & DOLABELA, F. & 18 \\
\hline 8 & $\begin{array}{l}\text { O empreendedor: fundamentos da iniciativa } \\
\text { empresarial. São Paulo: MacGraw-Hill, } 1989 .\end{array}$ & DEGEN, R. & 15 \\
\hline 9 & $\begin{array}{l}\text { Empreendedorismo e o espírito } \\
\text { empreendedor: uma análise da evolução dos } \\
\text { estudos na produção acadêmica brasileira. In: } \\
\text { EnANPAD, } 26 ., 2002 \text {, Salvador. Anais... Salvador: } \\
\text { ANPAD, } 2002 .\end{array}$ & $\begin{array}{l}\text { PAIVA Jr., F.G.; BARBOSA, } \\
\text { F.; CORDEIRO, A. T. }\end{array}$ & 14 \\
\hline 10 & $\begin{array}{l}\text { Intrapreneuring: por que você não precisa } \\
\text { deixar a empresa para tornar-se um } \\
\text { empreendedor. São Paulo: Harbra, } 1989 .\end{array}$ & PINCHOT, G. & 14 \\
\hline 11 & $\begin{array}{l}\text { The achieving society. New York: VanNostrand, } \\
1961 .\end{array}$ & McCLELLAND, D. & 14 \\
\hline 12 & $\begin{array}{l}\text { Entrepreneuriat: um champ fertile à la } \\
\text { recherche de son unité. Revue française de } \\
\text { gestión, v.28, n.138, p.109-125, } 2002 \text {. }\end{array}$ & DANJOU, I. & 12 \\
\hline
\end{tabular}




\begin{tabular}{|c|c|c|c|}
\hline & Obras mais Citadas & Autor(es) & Mençöes \\
\hline 13 & O Segredo de Luísa. São Paulo: Cultura, 1999. & DOLABELA, F. & 12 \\
\hline 14 & $\begin{array}{l}\text { A conceptual framework for describing } \\
\text { the phenomenon of new venture creation, } \\
\text { Academy of Management Review, v. 10, n.4, p. } \\
696-706,1985 .\end{array}$ & GARTNER, W.B. & 11 \\
\hline 15 & $\begin{array}{l}\text { Clarifying the entrepreneurial orientation } \\
\text { construct and linking it to performance. The } \\
\text { Academy of Management Review, v.21, n.1, p.135- } \\
172,1996 .\end{array}$ & $\begin{array}{l}\text { LUMPKIN, G.T.; } \\
\text { DESS, G.G. }\end{array}$ & 11 \\
\hline 16 & $\begin{array}{l}\text { Empreendedorismo corporativo. Rio de Janeiro: } \\
\text { Elsevier, } 2003 .\end{array}$ & DORNELAS, J. C. A. & 11 \\
\hline 17 & $\begin{array}{l}\text { Essay on the Nature of Commerce in General. } \\
\text { New Brunswick: Transaction Publishers, } 2001 .\end{array}$ & CANTILLON, R. & 10 \\
\hline 18 & $\begin{array}{l}\text { Guest editors' introduction: corporate } \\
\text { entrepreneurship. Strategic Management } \\
\text { Journal, v.11, n.4, p.5-15, } 1990 \text {. }\end{array}$ & GUTH, W. D.; GINSBERG, A. & 10 \\
\hline 19 & $\begin{array}{l}\text { A Paradigm of Entrepreneurship: } \\
\text { entrepreneurial management. Strategic } \\
\text { Management Journal, v. 11, n.1, p. 17-27, } 1990 .\end{array}$ & $\begin{array}{l}\text { STEVENSON, H. H.; } \\
\text { JARILLO, J. C. }\end{array}$ & 9 \\
\hline 20 & $\begin{array}{l}\text { The Meaning of "Social Entrepreneurship". } \\
\text { Ewing Marion Kauffman Foundation and } \\
\text { Standford University. } 1998 .\end{array}$ & DEES, J.G. & 9 \\
\hline 21 & $\begin{array}{l}\text { Who is an entrepreneur? Is the wrong question. } \\
\text { American Journal of Small Business, v. 12, n. 4, p. } \\
11-32,1988 .\end{array}$ & GARTNER, W.B. & 9 \\
\hline 22 & $\begin{array}{l}\text { Differentiating Entrepreneurs from Small } \\
\text { Business Owners. Academy of Management } \\
\text { Review, v. 9, n. 2, p. 354-9, } 1984 .\end{array}$ & $\begin{array}{l}\text { CARLAND J.W.; } \\
\text { HOY, F.; BOULTON, W.R. }\end{array}$ & 8 \\
\hline 23 & $\begin{array}{l}\text { Formal Entrepreneurship Theory Economics: } \\
\text { existence and bounds. Journal of Business } \\
\text { Venturing, v. 8, n. 3, p. 197-210, } 1993 \text {. }\end{array}$ & BAUMOL, W. J. & 8 \\
\hline
\end{tabular}

Fonte: Elaborado pelos Autores com base nos Anais dos eventos da ANPAD (2001 a 2012).

As obras apresentadas podem ser consideradas como relevantes aos pesquisadores em empreendedorismo. Aos iniciantes, em particular, considera-se como uma literatura quase que obrigatória. Acredita-se que a sistematização das principais obras no campo do empreendedorismo pode ser útil no avanço e amadurecimento dos trabalhos futuros nesta temática. 


\section{CONSIDERAÇÕES FINAIS}

A pesquisa teve como objetivo analisar a produção científica com base nos artigos apresentados nos eventos da ANPAD entre os anos de 200I e 20I2. Nesse sentido, é válido retomar as questões de pesquisa que guiaram o estudo: a) quais as características da produção científica sobre empreendedorismo apresentada nos eventos da ANPAD? e b) quais os principais autores, bibliografias e temas tratados pelos pesquisadores? A sistematização das informações e análises realizadas permitiu responder adequadamente as indagações. Foi possível apresentar ao longo do artigo os principais autores, bibliografias e temas tratados pelos pesquisadores brasileiros no âmbito dos encontros da ANPAD.

De maneira complementar aos resultados apresentados, considera-se necessário pontuar que a pesquisa sobre empreendedorismo no Brasil encontra-se, provavelmente, em um estágio inicial, dado que há uma dispersão de temas e pesquisas eminentemente descritivas e que, portanto, pouco contribui para o avanço do conhecimento.

Além disso, verificaram-se diversos trabalhos pontuais e pouco articulados entre si, inclusive dentro de uma mesma IEs. Embora isso seja comum para um tema recente como o empreendedorismo, é preciso considerar a necessidade de uma maior articulação entre as instituições e os pesquisadores, por meio de redes e, neste contexto, a construção de linhas de pesquisa mais consistentes chegando até mesmo a articulações interinstitucionais. Isso seria uma alternativa para trabalhar em pesquisas mais robustas e com vistas aos resultados de médio e longo prazo. Tal proposição se torna mais relevante, na medida em que se constatou um desequilíbrio das produções acadêmicas, tanto do ponto de vista geográfico como institucional.

As 5 IES que mais apresentaram artigos no período considerado foram responsáveis por 76 trabalhos, ou seja, $5 \mathrm{I} \%$ do total, o isso indica que a produção na temática do empreendedorismo encontra-se centralizada em poucas instituições. A partir da décima sexta instituição listada, verificouse que a produção científica é bastante pulverizada, na medida em que $2 \mathrm{I}$ IES apresentaram apenas um artigo ao longo de doze anos. Nesse sentido, 
parece haver um desafio concreto no sentido de se ampliar e fortalecer a produção científica em empreendedorismo no país, sobretudo nas IEs com baixa produção acadêmica, sobretudo nas regiões norte e centro-oeste.

Em relação à análise temática foi possível perceber uma ampla diversidade de temas tratados. Por um lado, isso é reflexo dos diferentes interesses individuais dos pesquisadores sobre o empreendedorismo. Por outro, pode revelar a ausência de centros de estudos e até mesmo linhas de pesquisa pouco consistentes, ou seja, existe a necessidade de se tratar a temática do empreendedorismo dentro de um processo de investigações que estejam ancoradas em práticas que articulem os esforços empreendidos ao longo do tempo.

Neste contexto, vale observar que os artigos analisadores se limitaram, em grande parte, a fase exploratória, não evoluindo para a construção de estudos de natureza explicativa, o que provoca, muito provavelmente, a descontinuidade dos temas que são desenvolvidos nos estudos da área. Contudo, como em outras áreas da Administração, o número de artigos teórico-empíricos que utilizam métodos quantitativos e multimétodos pode vir a aumentar nos próximos anos e isso, em princípio, pode contribuir no amadurecimento neste campo de conhecimento.

A principal limitação da pesquisa se refere ao universo pesquisado, limitado aos eventos da ANPAD. Analisar a produção científica em teses, dissertações e artigos publicados em periódicos de alto impacto, nacionais e internacionais, se faz necessária para que as conclusões sejam ampliadas e fortalecidas. Da mesma forma, por limitações de tempo, percebe-se que uma análise mais detalhada, com mais cruzamentos entre os dados e informações obtidos podem ser feitos em pesquisas futuras - por exemplo: inserir na análise o fator de impacto das revistas e journals analisados e também quais são os artigos recentes mais relevantes e também quais são os artigos que mais tempo ficam como referências na área de Empreendedorismo. Além disso, indica-se que se investigue a influência do idioma sobre a produção científica brasileira, ou seja, em que medida isso tem sido um limitador nos resultados. No entanto, acredita-se ter contribuído no sentido de buscar achados que pudessem colaborar, desde já, com os pesquisadores e demais envolvidos com o campo do empreendedorismo no país. 


\section{REFERÊNCIAS}

AMIT, R.; GLOSTEN, L.; MULLER, E. Challenges to theory development in entrepreneurship research. Journal of Management Studies, v. 30, n. 5, p. 815-834, 1993.

BERTERO, C. O.; VASCONCELOS, F. C.; BINDER, M. P. Estratégia empresarial: a produção científica brasileira entre 1991 e 2002. Revista de Administração de Empresas, v. 43, n. 4, p. 48-62, 2003.

BERTERO, C. O. Ser ou não ser (boa) teoria: eis a questão. In: BERTERO, C.O.; CALDAS, M.P.; WOOD JR, T. (Org.). Produção científica em administração no Brasil, v. 1, cap. 1, p.1-17, São Paulo: Atlas,, 2005.

BOAVA, D. L. T.; MACEDO, F. M. F. Estudo sobre a essência do empreendedorismo. Anais... EnANPAD, Salvador, 30., 2006.

BORGES, C.; BORGES, M. M.; FERREIRA, V. R.; NAJBERG, E.; TETE, M. F. Empreendedorismo sustentável: proposição de uma tipologia e sugestões de pesquisa. Anais... EnANPAD, Rio de Janeiro, 35., 2011.

BOSCZOWSKI, A. K.; TEIXEIRA, R. O Empreendedorismo sustentável e o processo empreendedor: em busca de oportunidades de novos negócios como solução para problemas sociais e ambientais. Anais... EnANPAD, São Paulo, 33., 2009.

BYGRAVE, W.; HOFER, C. Theorizing about entrepreneurship. Entrepreneurship Theory \& Practice, v. 16, n. 2, p. 13-22, 1991.

CANTILLON, R. Ensaio sobre a Natureza do Comércio em Geral. Curitiba: Segesta, 2002. CASSOL, N. K.; SILVEIRA, A.; HOELTGEBAUM, M. Empreendedorismo feminino: análise da produção científica da base de dados do Institute for Scientific Information (ISI), 1997-2006. 2007. Anais... EnANPAD, Rio de Janeiro, 31., 2007.

CARDOSO, A.L.J.; SUZIMÉRI VILAS BOAS PESCADOR, S.V.B.P.; QUANDT, C.O. A influência da percepção sobre inovação, criatividade, aprendizagem e empreendedorismo na avaliação de casas noturnas. Anais... EnANPAD, Rio de Janeiro, 36., 2012.

CORDEIRO, A. C.; MELLO, S. C. B. Rupturas, permanências e ressignificações na estrutura discursiva do empreendedorismo. Anais... EnANPAD, Salvador, 30., 2006.

COOPER, H. M.; LINDSAY, J. J. Research synthesis and meta-analysis. In: BICKMAN, L.; ROG, D. J. Handbook of applied social research methods. London: Sage Publications, p. 315342, 1998.

FIALA, N. As incubadoras como ambientes de aprendizagem do empreendedorismo.

Anais... EnANPAD, Rio de Janeiro, 36., 2012.

FONTENELE, R. E. S.; SOUSA, P. F. B.; LIMA, A. O. Empreendedorismo, crescimento econômico e competividade dos BRICS: uma análise empírica a partir dos dados do GEM e GCI. Anais... EnANPAD, Rio de Janeiro, 35., 2011. 
FREITAG, A. R.; FILHO, AMAL, M. Estratégias e determinantes da internacionalização de pequenas e médias empresas (PMEs): abordagem da teoria de redes de relacionamento e empreendedorismo. Anais... EnANPAD, Rio de Janeiro, 32., 2008.

FREITAS, A. A. F.; RIBEIRO, R. C. L.; LOBO, R. J. S.; LIMA, A.; PEÑALOZA, V. Cultura, religião e empreendedorismo: O lócus de controle de comerciantes de cidades religiosas. Anais... Simpósio de Gestão da Inovação Tecnológica, Brasília, 25., 2008.

GOMES, D. T.; GUERRA, P. V.; VIEIRA, B. N. O desafio do empreendedorismo feminino. Anais... EnANPAD, Rio de Janeiro, 35., 2011.

GOMES, A. F.; SANTANTA, W. G.; ARAÚJO, U. P. Empreendedorismo feminino: o estado-da-arte. Anais... EnANPAD, São Paulo, 33., 2009.

GREBEL, T.; PYKA, A.; HANUSCH, H. An evolutionary approach to the theory of entrepreneurship. Industry and Innovation, v. 10, n.4, p. 493-514, 2003.

HASHIMOTO, M.; ANDREASSI, T.; ARTES, R.; NAKATA, L. E. Relações entre intraempreendedorismo, clima organizacional e desempenho financeiro - um estudo sobre as melhores empresas para se trabalhar no Brasil. Anais... EnANPAD, Rio de Janeiro, 34., 2010.

HENRIQUE, D. C.; CUNHA, S. Metodologias, recursos e práticas didático-pedagógicas no ensino de empreendedorismo em cursos de graduação e pós-graduação nacionais e internacionais. Anais... EnANPAD, Salvador, 30., 2006.

IIZUKA, E. S.; SANO, H. O terceiro setor e a produção acadêmica: uma visita aos anais dos ENANPAD's de 1990 a 2003. Anais... EnANPAD, Curitiba, 28., 2004.

KEINERT, T. M. M. O que é administração pública no Brasil. Anais... EnANPAD, Florianópolis, 24., 2000.

LEITE, Y. V. P.; MORAES, W. F. A. Empreendedorismo Internacional: Proposição de um Framework. Anais... EnANPAD, Rio de Janeiro, 36., 2012.

LIMA, B.; SILVA, K. L.; CONDE, D. R. Empreendedorismo em empresas familiares: intraempreendedorismo e famílias empreendedoras. Anais... Encontro de Estudos Organizacionais da ANPAD. Florianópolis, 6., 2012.

LIMA, E.; LOPES, R. M.; NASSIF, V. M. J. Desafios e oportunidades para aperfeiçoar a educação superior brasileira. Anais... EnANPAD, Rio de Janeiro, 36., 2012.

MACHADO, H. V.; SILVA, T.; NASCIMENTO, M. R. Empreendedorismo e redes: a exploração de oportunidades em associações comerciais. Anais... EnANPAD, São Paulo, 33., 2009.

MARCONI, M. A.; LAKATOS, E. M. Técnicas de Pesquisa. São Paulo: Atlas, 1990.

MOREIRA, S. V. Análise documental como método e como técnica. In: DUARTE, J.; BARROS, A. (Org.). Métodos e técnicas de pesquisa em comunicação, v.1, cap.17, p. 269-279, São Paulo: Atlas, 2005. 
NASSIF, V. M. J. ; SILVA, N. B.; ONO, A. T.; BONTEMPO, P.C.; TINOCO, T. Empreendedorismo: Área em Evolução? Uma Revisão dos Estudos e Artigos Publicados entre 2001 e 2008. Anais... EnANPAD, São Paulo, 33., 2009.

PAIVA, F. G., JR; CORDEIRO, A. T. Empreendedorismo e o espírito empreendedor: uma análise da evolução dos estudos na produção acadêmica brasileira. Anais... EnANPAD, Salvador, 26., 2002.

PAIVA, F. G. JR.; ALMEIDA, L. F.; OLIVEIRA, M. A. Uma Experiência Dialógica de Ensino no Curso de Graduação em Administração. Anais... Encontro de Ensino e Pesquisa em Administração e Contabilidade, Recife, 1., 2007.

PAULA, M. B.; OLIVERO, S. M.; MURITIBA, P. M.; MURITIBA, S.N. Produção sobre terceiro setor no Brasil: pontualidade, dispersão e lacunas teóricas. Anais... EnANPAD, Rio de Janeiro, 34., 2010.

PEREIRA, G. D. F.; CORDEIRO, A. T.; SILVA, M. A. P.; BATISTA, M. M. Empreendedorismo regional: um olhar sobre a identidade cultural em narrativas locais. Anais... EnANPAD, Rio de Janeiro, 36., 2012.

QUENTAL, C.; WETZEL, U. Equilíbrio trabalho-vida e empreendedorismo: a experiência das mulheres brasileiras. Anais... EnANPAD, Salvador, 26., 2002.

SAY, J. B. Treatise on Political Economy: On The Production, Distribution and Consumption of Wealth, Kelley, New York: Kelley, 1964.

SILVA, A. S.; MARTINS, H. C. Empreendedorismo social: um estudo da relação entre os elementos constituintes do empreendedorismo e a gestão de organizações sociais. Anais... EnANPAD, Rio de Janeiro, 34., 2010.

SCHUMPETER, J. A. Theory of economic development: an inquiry into profits, capital, credit, interest and the business cycle. Cambridge: Harvard University Press, 1934.

SERAFIM, M. C.; MARTES, A. C. B.; RODRIGUEZ, C. L. Segurando na mão de Deus: organizações religiosas e estruturas de suporte ao empreendedorismo. Anais... EnANPAD, Rio de Janeiro, 34., 2010.

SILVEIRA, A.; ROPELATO, M.; VIEIRA, S. S.; NASCIMENTO, S. Empreendedorismo em diferentes tipos de organizações: análise da produção científica na base de dados SciELO: 2004-2008. Anais... EnANPAD, Rio de Janeiro, 34., 2010.

TONELLI, D. F.; BRITO, M. J.; ZAMBALDE, A. L. Empreendedorismo pela ótica da teoria ator-rede: explorando alternativa às perspectivas subjetivista e objetivista. Anais... Simpósio de gestão da Inovação Tecnológica da ANPAD, 26., 2010.

ZAMPIER, M. A.; TAKAHASHI, A. R. Intraempreendedorismo feminino, competências empreendedoras e conflito trabalho-família: um estudo de caso com professoras de programas de mestrado e doutorado em administração. Anais... Encontro da Divisão de Estudos Organizacionais da ANPAD, 6., 2010. 


\section{DADOS DOS AUTORES}

EDSON SADAO IIZUKA* esadao@fei.edu.br

Doutor em Administração Pública pela FGV- EAESP

Instituição de vinculação: Centro Universitário FEI

São Paulo/SP - Brasil

Áreas de interesse em pesquisa: Negócios Sociais, Ensino e Pesquisa em Administração e Gestão Social.

*Centro Universitário FEI-PPGA Rua Tamandaré, 688, $5^{\circ}$ andar

Liberdade São Paulo/SP 01525-000

\section{GUSTAVO HERMÍNIO SALATI MARCONDES DE MORAES}

gustavo.salati@fca.unicamp.br

Doutor em Administração pela FGV-EAESP

Instituição de vinculação: Faculdade de Ciências Aplicadas - Universidade Estadual de Campinas

Limeira/SP - Brasil

Áreas de interesse em pesquisa: Empreendedorismo e Tecnologia da Informação.

ANDERSON DE ANDRADE SANTOS andersons@sc.usp.br Mestre em Engenharia de Produção pela USP - Escola de Engenharia de São Carlos Instituição de vinculação: Instituto de Ensino e Pesquisa (Insper)

São Paulo/SP - Brasil

Áreas de interesse em pesquisa: Relacionamento e desenvolvimento de fornecedores. 